\title{
Correction to: Development of Wireless Sensor Node and Controller Complying with Communication Interface Standard for Smart Farming
}

\author{
Soo-Hyun Park ${ }^{1}$ Tusan Park ${ }^{2} \cdot$ Heun Dong Park ${ }^{3} \cdot$ Dae-Hyun Jung ${ }^{1,4} \cdot$ Joon Yong Kim ${ }^{5}$ \\ Published online: 16 June 2020 \\ (C) The Korean Society for Agricultural Machinery 2020
}

Correction to: Journal of Biosystems Engineering (2019) 44:41-45

https://doi.org/10.1007/s42853-019-00001-5

Due to an unfortunate oversight the history line has been omitted. It should be read:

Received: 4 November 2018

Revised: 20 February 2019

Accepted: 24 February 2019

The online version of the original article can be found at https://doi.org/ 10.1007/s42853-019-00001-5

Joon Yong Kim

tombraid@snu.ac.kr

1 Smart Farm Research Center, Korea Institute of Science and Technology (KIST), Gangneung, Gangwon-do, Republic of Korea

2 Department of Bio-Industrial Machinery Engineering, Kyungpook National University, Daegu, Republic of Korea

3 Research Team, Jinong Inc., Anyang, Gyeonggi-do, Republic of Korea

4 Department of Biosystems Engineering, Seoul National University, Seoul, Republic of Korea

5 Research Institute for Agriculture and Life Sciences, Seoul National University, Seoul, Republic of Korea 